\title{
Extending the technological capability of turning operation
}

\author{
Tareq A. Abu Shreehah \\ Tafila Technical University, Department of Mechanical Engineering, P. O. Box: 3588, Amman 11953, JORDAN \\ E-mail: tarek_shreehah@yahoo.com
}

\begin{abstract}
The main goal of this paper is to compensate the elastic deformations of the technological system in order to achieve maximum cross sectional accuracy and productivity of turning operation with minimum cost. This study was based on developing of mechanical adaptive system (MAS) for accuracy control by dynamic adjustment of the tool position during processing. The dynamic characteristic of components of the engine lathe technological system supplied with the proposed MAS was studied, and a mathematical model was obtained and presented as a system with one degree of freedom in the direction of Z-axis. The stable zones of operating were defined using Leonarion graphic method. The optimal cutting parameters correspond to stationary positions of equilibrium were obtained when processing heat resistant steel under the following conditions: feed rate, $\mathrm{S}$, ranges from 0.07 to $0.39 \mathrm{~mm} / \mathrm{rev}$; depth of cut, $\mathrm{t}$, ranges from 0.5 to $1.5 \mathrm{~mm}$; and turning speed, $v$, ranges from 0.55 to $1.45 \mathrm{~m} / \mathrm{sec}$. Experimental examination of the proposed system showed that the use of adaptive control may overcome the error appeared due to the elastic deformation of the technological system. The maximum circularity deviation of the processed, using the developed MAS, cylindrical surfaces did not exceed 40 microns, whereas 98 microns of maximum deviation was reached using usual cutter. The developed MAS can, in number of cases, replace the cylindrical external grinding processing by usual cutting on lathe machine tools, providing thus the rigid requirements on dimensional and form accuracy in cross sections.
\end{abstract}

Keywords: Control systems, cross sectional accuracy, mechanical adaptive, productivity, turning

\section{Introduction}

Metal cutting process or machining represents a general-purpose technique for machine parts and mechanisms. At present, the share of metal cutting in the engineering industries constitutes about 35 percent of all manufacturing processes and therefore, its influence is of prime importance in the rate of development of mechanical engineering (Arshinov and Alekseev, 1976, Abu Shreehah, 2002).

Automation of the cutting processes is the turnpike in the direction of development in machine building technology. An introduction, on the basis of automation, of humanless technology in metal working and assembly processes especially in establishment of flexible production systems put forth the problem of automatic conforming the manufactured product quality. It is not possible to solve this problem without the presence of reliable systems of quality control which automatically permit to obtain the required accuracy parameters of processed parts.

The flexible production modules, which are the foundation of flexible production systems, consist of CNC machine tool, industrial robot and a series of other systems (transport, directing or controlling, instrumental, etc.). The human exclusion from the participation in parts manufacturing calls to equip the robotic modules with automatic systems of quality control. Recently, more attention is given to turning modules as one of the first robotic modules. This may be described by the significance of extending the technological capability of the operation.

It is well known that in all metal cutting processes, including turning, deviations in dimensions, surface profile and orientation of the machined parts may occur. These errors lead to low durability and reliability of the parts and articles. Moreover, these deviations bear accidental character, because they appear under the influence of various accidental factors such as tool wear, thermal and elastic deformations of technological system consisting of machine-fixture-tool-workpiece (Abu Shreehah, 2002a). 
Several methods are used to decrease the effect of the different factors that generate the deviations in the turned parts and reduce the operation productivity. These methods are the processing at lower cutting conditions to reduce the cutting forces and its variation and hence the elastic and thermal deformations of the technological systems will be reduced; the turning in several passes; the stabilization of the thermal deformations of the technological systems; the storing of the workpieces in groups to decrease the effect of variation in machining allowance and parts hardness; the improving of the accuracy and rigidity of the technological system; etc. Theses methods are based on reduction the processing errors at the expense of missing the productivity and increasing the manufacturing cost. Other methods are accuracy improvement by compensating for the error through control technology. Via the methods of control technology, the inherent error in machine tools is minimized by making use of available sensing, actuation and computer control techniques. Many studies have been carried out to improve the accuracy of machining by using such methods. For instance, Zhan-Qiang (1999) used a repetitive error measurement and compensation scheme to improve the workpiece diameter accuracy for $\mathrm{CNC}$ turning. The scheme entailed an on-machine measurement and error compensation technology between machining processes. The workpiece diameters were measured along the workpiece length by using a fine touch sensor and then were modified in the compensation program for implementation of next pass error correction. It is obvious that the proposed scheme is not applicable when the cutting operation is consisting of one cutting pass.

Analyses of works and researches (Abu Shreehah, 2002b; Balakshin, 1973; Skragan, Joukov and Kadirov, 1984) show that at the incomplete initial data on the course of cutting process, the means of adaptive control are considered a suitable method of effective management of cutting process for the purpose of achievement the maximum quality and productivity with minimum cost.

Several hydraulic, electrical, optical and other systems were used as early as the beginning of the second half of the 20 century (Abu Shreehah, 2002b). An adaptive control (AC) system was described for turning on a lathe by Oren Masorya et al. (1980). In this system, a programmed cutting force was compared with the actual cutting force; the difference provides correction to the feed. It was demonstrated that the effective AC loop gain depends on both depth-of-cut and spindle speed and thereby influence system stability. The major disadvantage of such systems related to delay in processing initial data and making correction, which is necessary for realization of technological system to obtain the given requirements. Moreover, such systems require special measuring, converting, and intensifying devices, which are the reason of their low reliability.

The mechanical adaptive systems (MAS) have many advantages over the hydraulic, electrical and optical systems. They are simple in manufacturing and operation with high speed. In this case the disturbing factor is used as a managing signal for adjustment that approaches the moment of reception of the information about necessity realization adjustment to the moment of its execution. Besides, the mechanical adaptive systems do not require the above-stated special additional devices, that is the reason of their high reliability. An example of MAS was proposed by the author to overcome the error appeared in the longitudinal section profile of turned parts due to the elastic deformation of the technological system (Abu Shreehah, 2002a). For extending the capability of turning operation in the area of adaptive control technology, a study was made of an innovative approach. Thus, in the present study, a new simple MAS for compensating the error in the cross section profile of processed parts due to tool deflection is proposed. The developed system has a lowered rigidity and oscillating stability, and therefore needs to be analyzed in order to find the stable cutting regions and determine the cutting parameters which ensure the non- oscillating turning.

\section{Construction of the proposed system}

If it is necessary to form surfaces with small deviation in cross section, it is recommended to use the method of elastic adaptation of the technological system. The system of adaptive control of turning process which realized on this method, is based on the fact that the mechanical pliability is not always harmful and may be controlled.

As known, the total pliability of the technological system equals to the sum of the pliability of its separated elements. If in particular process of cutting, the pliability of any element has a negative sign, then the total pliability of the system might be zero. The carriage turn or roll-down may serve as an example.

On the basis of the above mentioned, it was proposed to introduce an additional mechanism in the technological system that possess a controllable pliability. The phenomenon of redistribution of the cutting force work was assumed in this system. In this case, the tangential component of cutting force Fz affects not only on the tool nose in the tangential direction, but also on the radial.

The constructive adaptive system, realized on the basis of the above described method, is presented in Figure 1. This system consists of front 1 and rear 2 panels. The cutting tool 3 with the insert 4 is fixed on the front panel. The tool shank 5 used to fix the system in tool holder is situated on one side of panel 2. On the other side, the wedge 6 is situated. The upper parts of panels 1 and 2 are jointed by an elastic element in the form of flat spring 7 which serves for retaining the front and rear panels in contact. The panels keep in contact in the middle part by the rolling bearing 8 and wedge 6 . With respect to the constructive execution, the bearing 8 has the capability to be displaced in both radial and tangential directions. The helical spring 9 is necessary to select the clearances between the contact components of the system. The arm 10 is used to control the motion of the panel 1 group upward, whereas, the arm 11 prevents the panel to be displaced in the axial direction.

The system works as follows: at the variation of cutting parameters, for example, the machining allowance or the workpiece hardness, the cutting force will be changed. An increase in the tangential component of the cutting force displaces panel 1 with the cutting element 4 in the same direction $(\mathrm{OZ})$. The panel 1 with the element 4 will over-run on wedge 6 and as a result, these 
components will also be displaced in the radial direction, and hence, the elastic deformations of the technological system will be compensated.

The proposed system of accuracy control possess rapid acting characteristic and can react on variations in cutting conditions in the limits of one revolution of the workpiece. Thus, this system permits to compensate the deviations appeared from the true circular shapes.

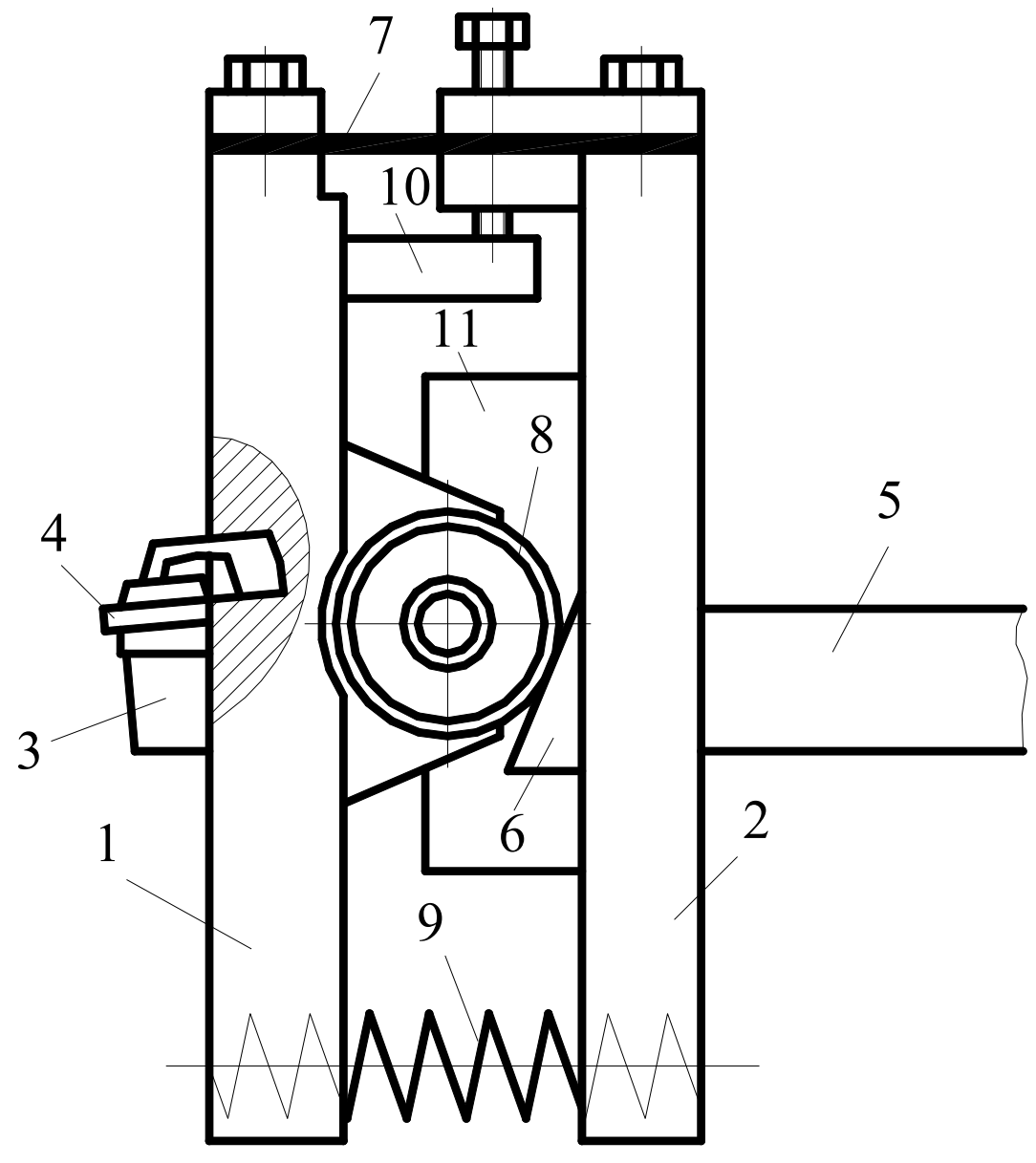

Figure 1. The developed mechanical adaptive system

\section{Analysis of the vibrational motion of the technological system}

At the turning operation carried with the help of adaptive system, the followings arise: the necessity in analyzing the oscillating motion of the technological system, the necessity of finding the stable cutting regions, and determining the cutting parameters which ensure the non-oscillating turning.

To analyze the oscillating motions of the technological system, it is necessary to define the rated mathematical model of the system and determine its parameters such as rigidity $(\mathrm{j})$, natural frequency $(f)$, reduced mass $(\mathrm{m})$, logarithmic decrement $(\Delta)$, and the proportional coefficient (h) between the resistance force and the speed (Murashkin and Murashkin, 1977).

\subsection{The rated mathematical model of the technological system}

The real technological system has a large numbers of degrees of freedom. The analysis of such systems is relatively complicated, and therefore, simplified schemes are used for practical problems. These schemes are characterized by certain numbers of degrees of freedom.

According to the simplified scheme, the most light in weight elements (components) are considered to be deprived from the mass and presented in the form of deformed inertialess connections. The remaining bodies are considered as mass points (concentrated masses) or absolutely solid bodies. In connection with this, and by neglecting the gyroscopic forces and the parametric vibrations in gear and belt drives, the technological system can be presented as a mechanical with certain mass points. 
According to what has been said, the technological system of turning operation was presented in the form of model with 12 degrees of freedom: the spindle group has 3 degrees of freedom, 3 for the tool holder, 3 for the proposed system, and 3 for the tail stock. The carriage group and the work to be machined were considered absolutely rigid.

When constructing the mathematical model of the system, it is possible to neglect some degrees of freedom, if these degrees are related with squared frequencies that differ from 3 to 5 times in comparison with the limiting frequencies of the system.

In connection with the considered system, it was established that the limiting frequency equaled to $126 \mathrm{~Hz}$ that corresponds to the natural frequency of the cutting tool (proposed adaptive system) in the direction of Z-axis. Therefore, the mathematical model may be represented by a system with one degree of freedom in Z-direction. The parameters of the oscillating contour of this system have the following values:

$$
\mathrm{j}=2611.6 \mathrm{~N} / \mathrm{m} ; \quad \Delta=0.191 ; \quad \mathrm{m}=4.147 \mathrm{~N} ; \quad \mathrm{h}=200.08 \mathrm{~N} \cdot \mathrm{sec} / \mathrm{m} .
$$

The natural frequency of the proposed adaptive system was determined experimentally with the help of impulse excitation method. The measurement was carried out by an arrangement installed on the base of the engine lathe. This arrangement consists of intensifier, light-ray oscilloscope, power supply and vibro-feeler.

The rigidity of the proposed system was also determined experimentally. The system was statically loaded by a resultant force of three components of the cutting force (axial Fx, radial Fy, and tangential Fz) with the help of special apparatus and dynamometer. The displacement of the system was fixed in $\mathrm{Y}$ and $\mathrm{Z}$ directions by a micro-indicator and then its rigidity was calculated. The rigidity of the remaining components of the technological systems was taken from the references.

The system reduced mass was calculated with the following equation:

$$
m=\frac{j}{\omega^{2}}=\frac{j}{(2 \pi f)^{2}}
$$

where

$\mathrm{j}=$ the rigidity of the proposed system

$\omega=$ the circular natural frequency

$f=$ the cylindrical natural frequency.

The logarithmic decrement $\Delta$ was determined by:

$$
\Delta=\frac{\ln \frac{A_{i}}{A_{i+1}}}{n}
$$

where $\mathrm{A}_{\mathrm{i}}$ and $\mathrm{A}_{\mathrm{i}+1}=$ the amplitudes of the natural frequencies that lag from each other at $\mathrm{n}$ period.

To calculate the proportional coefficient between the resistance force and the speed, the following equation was used:

$$
h=2 \Delta m f
$$

\subsection{Definition of the stable cutting conditions}

Large relative vibrations between the tool and the workpiece in metal cutting process reduce the productivity and accuracy of the manufacturing process (Boothroyd, 1975; Khraisheh et al., 1995; Wiercigroch and Krivtsov, 2001). This is particularly dangerous when a sudden and uncontrolled rise of vibration amplitude occurs. In many practical situations, the conditions in which such an instability appears can be satisfactorily explained by linear dynamics. However, more comprehensive insight can be gained only if the dynamic interactions between the machine tool and the cutting process are treated as nonlinear. An example of such behavior is self-excited oscillations, so-called chatter (Wiercigroch and Krivtsov, 2001).

Primary chatter may arise from different physical causes such as friction, the tendency of the cutting forces to change with the cutting speed, and the dynamical effects of the geometry of the cutting tool on the cutting process (Khraisheh, et al. 1995; Tobias 1961).

Several investigations into nonlinear dynamic have shown an existence and importance of chaotic motion occurring in machining. Studies (Tobias, 1961; Merchant, 1944) have modeled the dynamic progression, structural reasoning and stability limit of this vibration. The mathematical models developed in these studies assumed a straightforward and common behaviour. Other studies (Welbourn and Smith, 1970; Gradisek et al., 1996, Balkrishua and Shin, 1999, Gallina and Trevisani, 2003) have focused on specifying appropriate operational parameters as a means of preventing the accumulation of the expected vibrations. The fundamental principles of the vibration phenomena have established in studies (Clancy and Shin, 2002; Ema and Mauri, 2003). 
Previously, in most studies the vibration considerations were restricted solely to unpliable tool chatter. In this study the effect of the suggested system will be discussed.

In order to understand how self-excited chatter occurs, the dynamic of the cutting process must be understood, and the characteristics of the dynamic response must be well described (Khraisheh et al., 1995).

As well known, the movement stability of the technological system under the effect of external disturbances is determined by the system behavior near the equilibrium position. If the system, under the effect of arbitrarily small initial disturbance, removes from the equilibrium position then the system is unstable.

For the systems of metal cutting machines, there are stationary and oscillatory positions of equilibrium. The cutting parameters (speed, feed, and depth of cut) are constant in the stationary type of equilibrium. If the cutting parameters periodically change then the vibrating position of equilibrium takes a place in the system.

During parts processing on metal cutting machines, it will be necessary to aim for stationary position of equilibrium which obtained in most cases by eliminating the self-excited vibrating motion. The self-vibrating motion can be eliminated either by the rational selection of cutting parameters or by means of additional damping systems related with employing special amortizators of energy (dampers). The use of dampers complicates the technological system and, by far not always, it is not economically justified.

The analytical and graphic methods of determination the stable motion of the technological system are used for selecting the rational cutting parameters.

Finding the analytical solution of the differential equation, if it is possible, gives in most cases a great advantage. The analytical solution is obtained in algebraic form and does not require the introduction of numerical values of the process parameters or the initial conditions. Once, the solution is obtained, it is possible to set any numerical values and investigate the totality of the solutions described by the differential equation. However, it should be kept in mind that only few equations that describe the real system are enough simple and permit accurate solution.

The graphic methods of analysis are one of the important methods used for investigating different phenomena related with nonlinear vibration. With the help of graphic methods, the solutions of differential equations are sought in the form of integral curves on the phase-plane.

The isoclines, Lenarion and Delta methods can be referred to the graphic methods where the isoclines is the broadest. Isoclines method gives the opportunity to investigate the field of the integral curves with the help of graphics without solving the differential equation. This method is especially valuable when the accurate mode of solving the differential equation is not known. The principle demerit of isoclines method is the relatively long time required to carry it.

Lenarion method is particularly convenient for investigating the self-vibrating motion, and for other cases when the regenerating elastic force is linear with respect to the movement. This method does not require the approximation of the nonlinear characteristic and this is the principle merit of this method. The experimental characteristic may be used for constructing the integral curves.

The employment of isoclines and Lenarion methods for obtaining the graphic solution of the differential equation needs to fill all the phase-plane with segments of a straight lines that define the direction of the integral curves. Practically, if it is necessary to find only one integral curve, then some of these segments are used. In such cases the Delta-method is the most direct straight method for finding the required solution because it permits to get only the data directly related with the interested integral curve.

In order to keep the analysis clear, we will consider the stability of the one-degree-of-freedom model of the cutting process. The use of the Lenarion method will be presented in Figures 2 and 3 for turning operation of heat resistant steel with the help of the developed mechanical adaptive system. Number 1 in Figures 2 and 3 refers to the resistant force in the system, whereas, number 2 presents the characteristic of the tangential component of the cutting force, and number 3 indicates to the distribution characteristic obtained by adding characteristics 1 and 2 .

Under selection the work point on the dropping section of the distribution characteristic (Figure 2), the integral curve untwists from the unstable singular point $\mathrm{O}_{1}$, and aims to the stable cluster 4 . Here, a stationary self-vibrating motion, corresponding to light excitation, is established in the system. Thus, in this case, at the existence of self-vibrating motion, the cutting parameters will be changed with frequency equaled $126 \mathrm{~Hz}$.

If the work point is selected on the raised section close to the incident section (Figure 2), then two regimes are established in the technological system, stable and self-vibrating.

Under selection the work point on the raised section with clearly expressed positive resistance (Figure 3), the integral curve 5 will be twisted to the steady singular point $\mathrm{O}_{3}$. This indicates to the absence of the self-vibrating motion. The technological system in this case has steady stationary position of equilibrium and the cutting parameters used will be not changed.

By analyzing the movement of the technological system on the phase plane for all ranges of the cutting parameters, it is possible to define the steady regions and their corresponding cutting parameters.

Thus, the light and stringent excitation of self-vibrating motion may be occurring in the technological system. The stationary vibrating motion, corresponding light excitation, occurs at the dropping sections when a negative resistance is prevail in the system, whereas, the stringent excitation of self-vibrating or the steady stationary position of equilibrium may occur at the raised sections of distribution characteristic. 


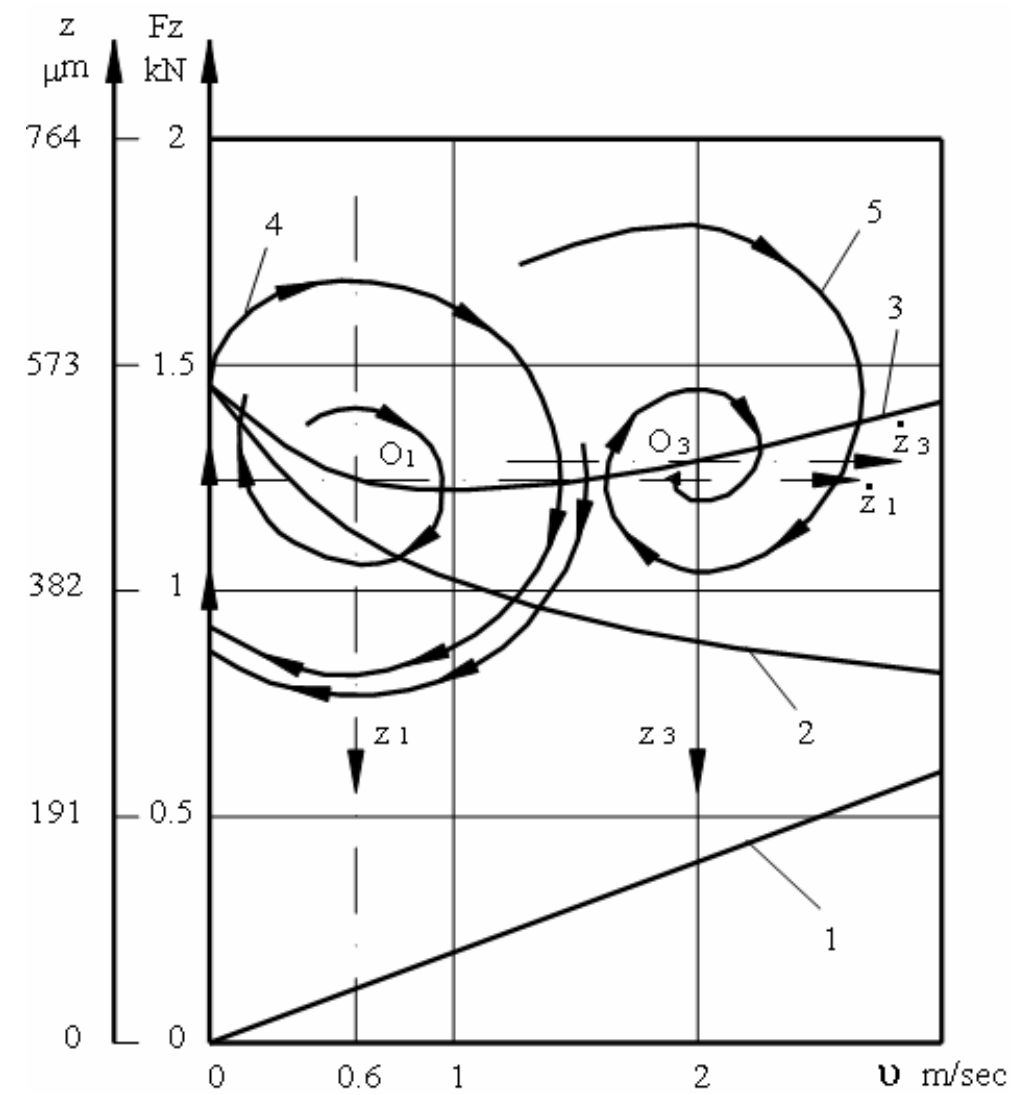

Figure 2. Phase portrait created by turning with the developed system at $v=0.6$ and $2 \mathrm{~m} / \mathrm{sec}, \mathrm{S}=0.39 \mathrm{~mm} / \mathrm{rev}$, and $\mathrm{t}=1.5 \mathrm{~mm}$

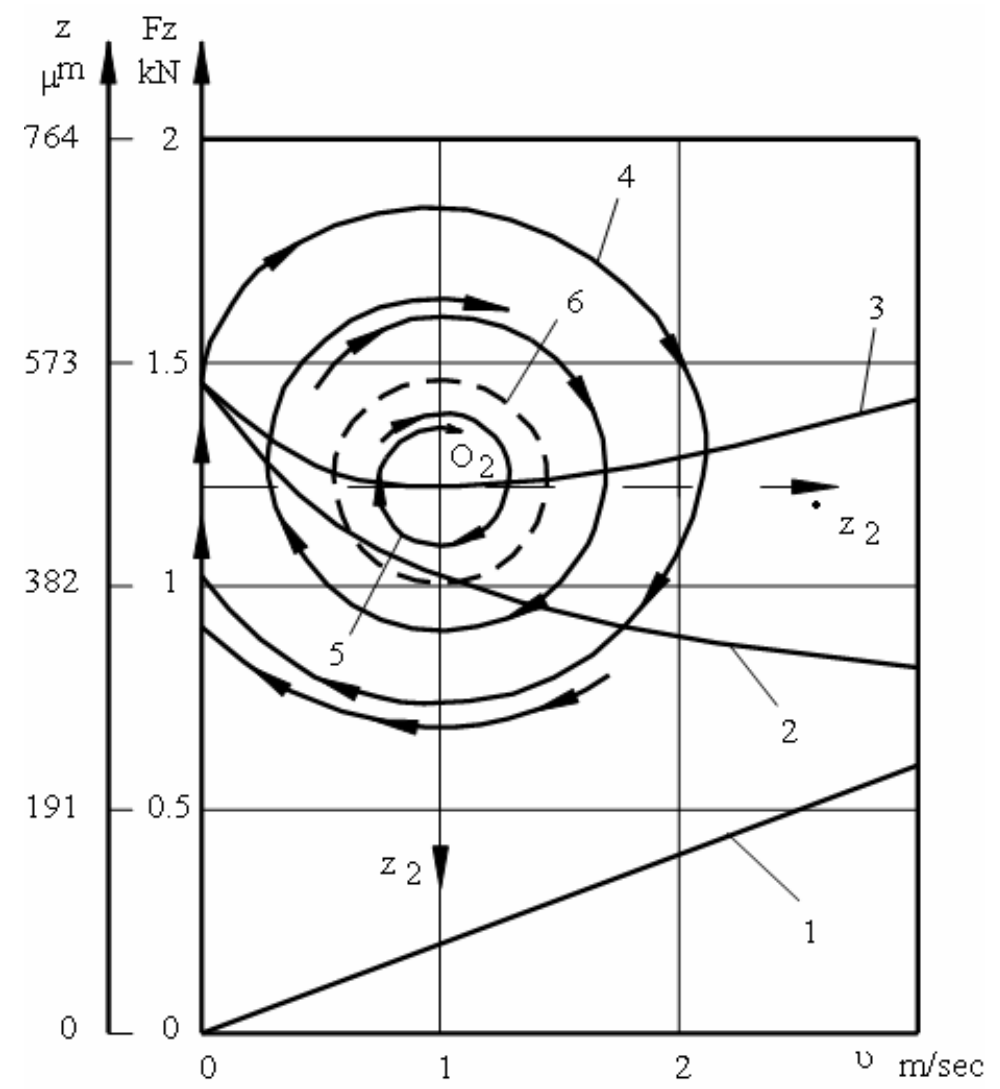

Figure 3. Phase portrait created by turning with the developed system at $v=1 \mathrm{~m} / \mathrm{sec}, \mathrm{S}=0.39 \mathrm{~mm} / \mathrm{rev}$, and $\mathrm{t}=1.5 \mathrm{~mm}$ 
As previously mentioned, the integral curves on the phase-plane give descriptive presentation about the character of the system movement at particular values of the system parameters. For evaluating the totality of phenomena that related to variation in this or other system-parameter, it is advisable to use the analytic method. The Later needs to construct the so called bifurcation diagram. During the last two decades, many works about bifurcation theory appeared (Guckenheimer and Holmes, 1983; Hagedorn, 1988; Kuznetsov, 1995; Parker and Chusa, 1989; Seydel, 1994). However, little is known about bifurcations of cutting manufacturing systems. The use of this method will be considered in forthcoming papers.

\section{Experimental testing of the developed system}

All experimental turning tests were carried out in a rigid Sigma 2600 engine lathe without removing the specimens.

\subsection{Workpiece material}

Turning trials were carried on groove circular bars of heat resistant steel which chemical composition in weight percent and mechanical properties are presented in Table 1. The work materials were received in the form of smooth round bars and prepared with two portions (A and B in Figure 4) such that each specimen could be turned with traditional turning tool and the proposed system without removing it. Each specimen was turned with the same conditions (cutting speed ( $v$ ), feed rate (S), and depth of cut (t)) as mentioned below. The specimens were held in a chuck and supported by the tail stock center. An emulsion lubricant was used during processing.

Table 1. Characteristics of the heat resistant steel to be machined

\begin{tabular}{|c|c|c|c|c|c|}
\hline \multicolumn{7}{|c|}{ Chemical composition, wt (\%) } \\
\hline $\mathrm{C}$ & $\mathrm{Si}$ & $\mathrm{Mn}$ & $\mathrm{Cr}$ & $\mathrm{W}$ & $\mathrm{V}$ \\
\hline 0.35 to 0.45 & 0.2 to 1.2 & 0.15 to 0.6 & 4.5 to 5.5 & 1.6 to 2.2 & 0.6 to 0.9 \\
\hline \multicolumn{7}{|c|}{ Mechanical properties } \\
\hline $\begin{array}{c}\text { Ultimate tensile } \\
\text { strength (MPa) }\end{array}$ & $\begin{array}{c}\text { Elongation } \\
(\%)\end{array}$ & $\begin{array}{c}\text { Reduction of area } \\
(\%)\end{array}$ & $\begin{array}{c}\text { Hardness } \\
\text { (HB) }\end{array}$ \\
\hline \multicolumn{2}{|c|}{ (\%) } & $10-13$ & $\geq 45$ & $\leq 345$ \\
\hline
\end{tabular}

\subsection{Turning conditions and tool material}

The specimens were turned with feed rate (S) ranged from 0.07 to $0.39 \mathrm{~mm} / \mathrm{rev}$, depth of cut (t) ranged from 0.5 to $1.5 \mathrm{~mm}$, and cutting speed (v) up to $3 \mathrm{~m} / \mathrm{sec}$. Cutting inserts made from white ceramics were used in the capacity of cutting tool. Ceramic is a highly efficient tool material that deprived of rare earth elements such as tungsten and cobalt, which offer the basic components of cemented carbide and high-speed steels. The ceramic tools find an application in semi-finish and finish turning of high strength and quenched cast iron, hardened steels and non-metallic materials (Abu Shreehah, 2003).

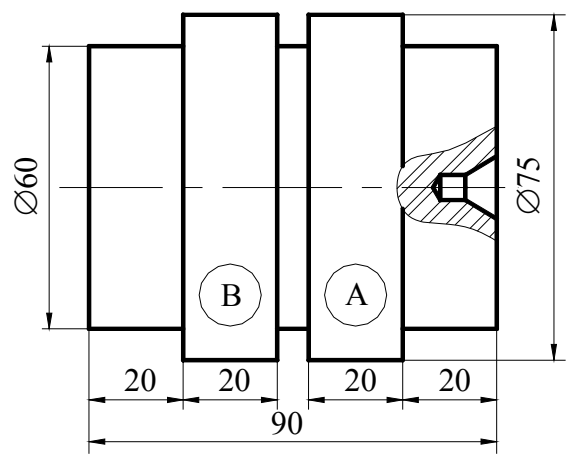

Figure 4. Workpiece geometry

\section{Experimental design}

In order to obtain better form quality, the proper setting of turning parameters is crucial before the process takes place. Recently, a Design of Experiment (DOE) has been implemented to select manufacturing process parameters that could result in a better quality product (Yang and Chen 2001). This study was carried out using Full Factorial Design $2^{3}$ which matrix is shown in Table 2 . 
Table 2. A $2^{3}$ in standard run order and the experimental results

\begin{tabular}{|c|c|c|c|c|c|c|c|c|}
\hline \multirow{2}{*}{ No. } & \multicolumn{2}{|c|}{ Feed rate, $\mathrm{S}$} & \multicolumn{2}{c|}{ Turning Speed, $v$} & Depth of cut, $\mathrm{t}$ & \multicolumn{2}{c|}{ Out-of-roundness in $\mu \mathrm{m}$ obtained At processing with } \\
\cline { 2 - 9 } & $\begin{array}{c}\text { Code } \\
\mathrm{X}_{1}\end{array}$ & $\begin{array}{c}\text { Actual } \\
\mathrm{mm} / \mathrm{rev}\end{array}$ & $\begin{array}{c}\text { Code } \\
\mathrm{X}_{2}\end{array}$ & $\begin{array}{c}\text { Actual } \\
\mathrm{m} / \mathrm{sec}\end{array}$ & $\begin{array}{c}\text { code } \\
\mathrm{X}_{3}\end{array}$ & $\begin{array}{c}\text { Actual } \\
\mathrm{mm}\end{array}$ & Usual cutter & The developed system \\
\hline 1 & -1 & 0.07 & -1 & 1 & -1 & 0.5 & 25 & 9 \\
\hline 2 & +1 & 0.39 & -1 & 1 & -1 & 0.5 & 55 & 21 \\
\hline 3 & -1 & 0.07 & +1 & 3 & -1 & 0.5 & 15 & 11 \\
\hline 4 & +1 & 0.39 & +1 & 3 & -1 & 0.5 & 28 & 18 \\
\hline 5 & -1 & 0.07 & -1 & 1 & 1 & 1.5 & 50 & 40 \\
\hline 6 & +1 & 0.39 & -1 & 1 & 1 & 1.5 & 29 & 24 \\
\hline 7 & -1 & 0.07 & +1 & 3 & 1 & 1.5 & 65 & 24 \\
\hline 8 & +1 & 0.39 & +1 & 3 & 1 & 1.5 & & \\
\hline
\end{tabular}

\subsection{Roundness test and results}

Roundness is of particular importance when designing components for fit and function. Data on deviations from the true circular shape when turning heat resistant steel are shown in Table 2. As expected, the use of the developed system has allowed forming surfaces with roundness variations in 3 times less comparatively with usual cutter. As an example, the roundness polar charts (Figures 5 and 6) traced by roundness instrument for surfaces processed at the same conditions are provided.

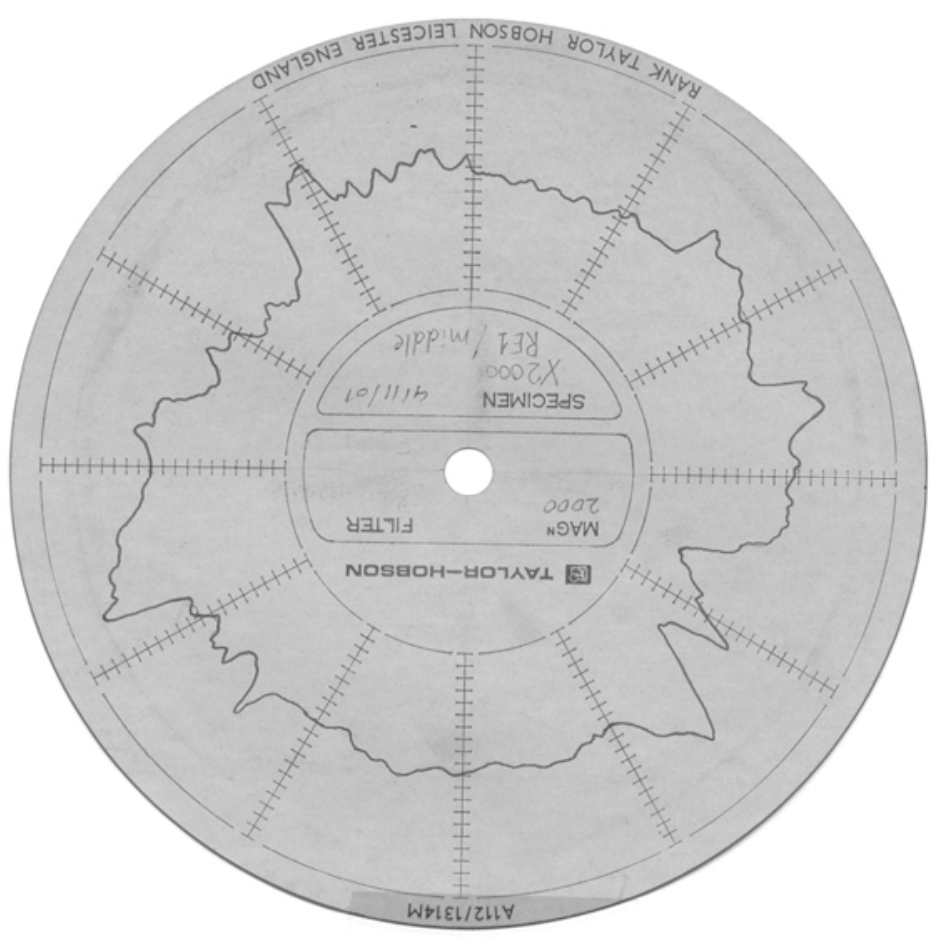

Figure 5. Roundness polar chart at 2000x illustrates circularity deviation created by turning with usual cutter at $\mathrm{S}=0.07 \mathrm{~mm} / \mathrm{rev}, \mathrm{t}=0.5 \mathrm{~mm}$, and $v=3 \mathrm{~m} / \mathrm{sec}$. 


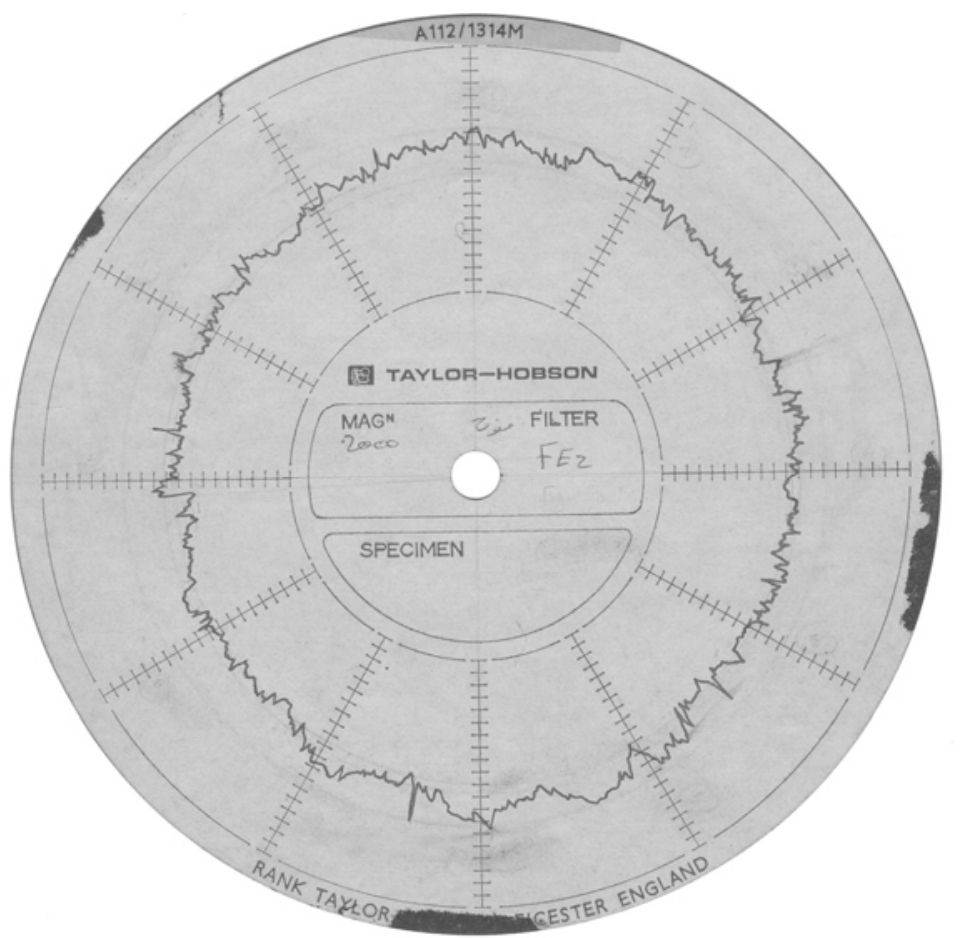

Figure 6. Roundness polar chart at 2000x illustrates circularity deviation created by turning with the developed cutter at $\mathrm{S}=0.07 \mathrm{~mm} / \mathrm{rev}, \mathrm{t}=0.5 \mathrm{~mm}$, and $v=3 \mathrm{~m} / \mathrm{sec}$.

\section{Conclusions}

The following conclusions are drawn from the study conducted:

1. An adaptive mechanical system for compensating the deviations in the cross-sections of the turned cylindrical parts has been developed and experimented. The proposed system corrects the tool setting at the moment of receiving information about the disturbing factor (the elastic deformation of the technological system). This system is simple in construction and does not require special additional devices that is the reason of its high reliability .

2. As a result of studying the dynamic characteristic of components of the engine lathe technological system, a mathematical model of the proposed adaptive system and the machine tool system was obtained and presented as a system with one degree of freedom in the direction of Z-axis. The stable zones of operating can be easily defined using Leonarion graphic method.

3. The optimal cutting parameters for the systems of metal turning machine supplied by the developed MAS correspond to stationary positions of equilibrium that obtained when processing under the following conditions: feed rate, $\mathrm{S}$, ranges from 0.07 to $0.39 \mathrm{~mm} / \mathrm{rev}$; depth of cut, t, ranges from 0.5 to $1.5 \mathrm{~mm}$; and turning speed, $v$, ranges from 0.55 to 1.45 $\mathrm{m} / \mathrm{sec}$.

4. The developed system has allowed forming surfaces with roundness variations considerably lesser than that obtained with usual cutter. The maximum circularity deviation of the processed cylindrical surfaces did not exceed 40 microns. Whereas, 98 microns of maximum deviation was reached using usual cutter.

5. Full Factorial Design of experiments was used to organize the experimental investigation.

6. An extended analysis of variance of the process parameters i.e. the cutting speed, feed and depth of cut to explore their effect on machining accuracy will be considered in the subsequent steps of investigation and forthcoming paper.

\section{Nomenclature}

$\mathrm{j} \quad$ Rigidity of the proposed system.

m Reduced mass.

$\omega \quad$ Circular natural frequency.

$f \quad$ Cylindrical natural frequency.

$\mathrm{A}_{\mathrm{i}} \quad$ Amplitude of the natural frequency.

$\mathrm{h} \quad$ Proportional coefficient between the resistance force and the speed.

$\Delta \quad$ Logarithmic decrement.

$v \quad$ Cutting speed.

S Feed rate. 
Depth of cut.

\section{References}

Abu Shreehah T., 2002a. Elastic deformation compensation of cutting technological system, Proceedings of the 14th European Simulation Multiconference ESM, Darmstadt, Germany, pp. 609-612.

Abu Shreehah T., 2002b. Calculation of elastic movements of the cutting technological system, Proceedings of the International Carpathian Control Conference ICCC’ 2002, Malenovice, Czech Republic, Pp. 113-118.

Abu Shreehah T., 2003. Studying of the capability of the cermet tools during turning of steels, Proceedings of the 44th SIMS Conference, Malardalen University, Sweden, pp. 299-303.

Arshinov V. and Alekseev G., 1976. Metal cutting theory and cutting tool design, Mir Publishers, Moscow.

Balakshin B. C., 1973. Adaptive control of the machine, Machine-building, Moscow.

Balkrishua C. R. and Shin C., 1999. A comprehensive dynamic cutting force model for chatter prediction in turning, International Journal of Machine Tools and Manufacture, Vol. 39, No. 10, pp. 1631-1654.

Boothroyd G., 1975. Fundamentals of metal machining and machine tools, McGraw-Hill, New York.

Clancy B. C. and Shin Y. C., 2002. A comprehensive chatter prediction model for face turning operation including tool wear effect, International Journal of Machine Tools and Manufacture, Vol. 42, No. 9, pp. 1035-1044.

Ema S. and Mauri E., 2003. Theoritical analysis on chatter vibration in drilling and its suppression, Journal of Materials Processing Technology, Vol. 138, No. 1-3, pp. 572-578.

Gallina P. and Trevisani A., 2003. On the stabilizing and destablizing effects of damping in wood cutting machines, International Journal of Machine Tools and Manufacture, Vol. 43, No. 9, pp. 955-964.

Gradisek J., Govekar E. and Grabec I., 1996. A choatic cutting process and determining optimal cutting parameter values using neural networks, International Journal of Machine Tools and Manufacture, Vol. 36, No. 10, pp. 1161-1172.

Guckenheimer J. and Holmes P., 1983. Nonlinear oscillations, dynamical systems, and bifurcation of vector fields, Applied Mathematical Sciences, Springer-Verlag, Vol. 42.

Hagedorn P., 1988. Nonlinear Oscillations, Oxford Engineering Science Series, 10, Oxford Science Publications, Oxford.

Khraisheh M. K., Pezeshki C. A., and Bayoumi E., 1995. Times series based analysis for primary chatter in metal cutting, Journal of Sound and Vibration, Vol. 180, No. 1, pp. 67-87.

Kuznetsov Y. A., 1995. Elements of applied bifurcation theory, Applied Mathematical Sciences, New York, Vol. 112.

Merchant, M. E., 1944. Basic mechanics of the metal cutting process, ASME Transactions Journal of Applied Mechanics, Vol. 11, No. 3, pp. 168-175.

Murashkin S. L. and Murashkin L. S., 1977. Applied Nonlinear Mechanics of Machine Tools, Mashinostroene, Leningrad.

Oren M., Yoram K. and Roland W., 1980. Adaptive control system for turning, CIRP Annals - Manufacturing Technology, Vol. 29, No. 1, pp. 281-284.

Parker T. S. and Chusa L. O., 1989. Practical Numerical Algorithms for Choatic Systems, New York, Springer-Verlag.

Seydel R., 1994. Practical bifurcation and stability analysis from equilibrium to chaos, Interdisciplinary Applied Mathematics, Vol. 5.

Skragan V. A., Joukov E. L., and Kadirov J. N., 1984. Using Experience of Adaptive System for Accuracy Control of Turning Operation, LDNTP, Leningrad.

Tobias, S. A., 1961. Machine Tool Vibration, Wiley, New York.

Wiercigroch M. and Krivtsov A. M., 2001. Frictional chatter in orthogonal metal cutting, Philosophical Transactions of the Royal Society, Vol. 359, Pp. 713-738.

Welbourn D. B. and Smith J. D., 1970. Machine Tool Dynamics - An Introduction, Cambridge University Press, London.

Yang J. L. and Chen J. C., 2001. A systematic approach for identifying optimum surface roughness performance in end-milling operations, Journal of Industrial Technology, Vol. 17, pp 1-8.

Zhan-Qiang L., 1999. Repetitive measurement and compensation to improve workpiece machining accuracy, International Journal of Advanced Manufacturing Technology, Vol. 15, pp. 85-89.

\section{Biographical notes}

Dr. Tareq A. Abu Shreehah is an Associate Professor in the Department of Mechanical Engineering Tafila Technical University, Jordan. He has engaged in teaching and research activities since the last 10 years. His research activities are in manufacturing engineering, including forming and machining processes. Dr Abu Shreehah has published more than 12 papers in refereed international journals and conferences.

Received December 2009

Accepted January 2010

Final acceptance in revised form March 2010 